\title{
ISOLATION AND IDENTIFICATION OF TWO SMOOTH MUSCLE STIMULANTS FROM MENSTRUAL FLUID
}

\author{
By Dr. G. EGLINTON, Prof. R. A. RAPHAEL, F.R.S., and DR. G. N. SMITH \\ Department of Chemistry, University of Glasgow \\ AND \\ DR. W. J. HALL and DR. V. R. PICKLES \\ Department of Physiology, University of Sheffield
}

$\mathrm{T}$ HE presence of a group of lipid smooth-muscle stimulants in menstrual fluid was first roportod in Nature in 1957 (rof. 1). Since then it has been shown that these substances, which aro almost certainly produced by tho endometrium in its secrotory phase ${ }^{2}$, are in part carried to tho myometrium, and there stimulate the rhythmical contractions of normal monstruation. An excess of such an effect is probably an important factor in causing the intense utorine cramps of primary dysmenorrhoes $^{3}$.

Two physiologically active constituents of high potency have now been isolated from monstrual extracts and, by methods doscribed here, have boen identifiod as prosta. glandins $\mathrm{PGE}_{2}$ and $\mathrm{PGF}_{2 \alpha}$.

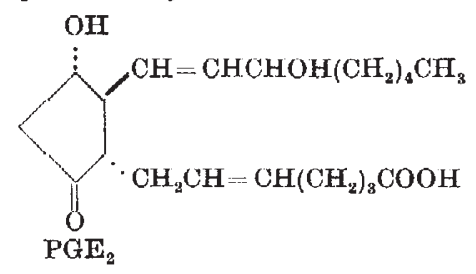

(11a,15-dihydroxy-9-keto-prosta-5,13-dienoic acid)<smiles>CCCCC(CC)OC=CC1C(O)CC[C@@H]1CC=CCC(=O)O</smiles>
$\mathrm{OH}$ $\mathrm{PGF}_{2 a}$

(9a,11a,15-trihydroxy-prosta-5,13-dionoic wid $)$

These substances are members of an important class of smooth-muscle stimulants originally dotocted by von Eulor", who introduced the name "prostaglandin'; the rocent outstanding invostigations of Borgström and his collongues have resulted in the separation and structural identification of five nuturally occurring individuals of this closely relatod group of compounds $s^{5,9,10,13,14}$.

The prostaglandins $\mathrm{PGE}_{8}$ and $\mathrm{PGF}_{2 u}$ are cortainly not the only active constituents present in menstrual fluid, but they do account for tho major part of the activity. Although these two components are only present in minuto amounts thoir high activity, detoctable at a concentration of $10^{-10} \mathrm{~g} / \mathrm{ml}$., permitted tho physiological offoct to bo discernod at an early stage ${ }^{6}$.

Preliminary fractionation results gave some indication that the active materials woro of the long-chain hydroxyacid typo?. This result, together with the nature of the activity shown, gave the first inkling that the substances involved might be mombers of the prostaglandin series. Accordingly, the separation techniques used so elogantly by Bergstrom's school in the isolation of the prostaglandins from more abundant sources were applied to the menstrual fluid derived from 3,675 specimens, collected and treatod ins described previously?. Successive extractions with acetono and dichloromethane producod a crude monstrual lipid concontrato (about $75 \mathrm{~g}$ ).

The treatment of this lipid ooneentrate is brielly outlined in Fig. 1. Assay of the active constituonts wets
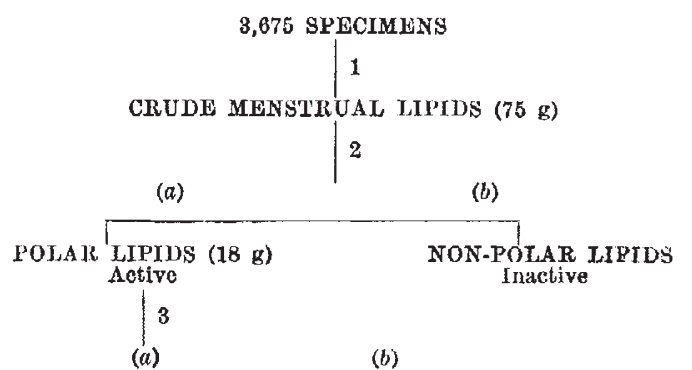

(b)

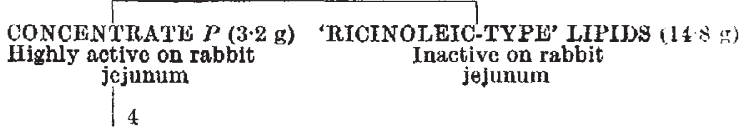

Eluant 1.4-2.01. Eluant 2.6-3.21.

CONCENTRATE $Q(165 \mathrm{mg})$ CONCENTRATE $R(85 \mathrm{mg})$

CONCEN'TRATE $U(0.5 \mathrm{mg})$ CONCENTRA'T $V(0.5 \mathrm{mg})$

Hig. 1. Fractionation scheme for the isolation of the active cunstituents from the menstrual specimens

(1) Acetonc and dichloromethane extraction (ref. 7). (2) Bhtion from hydrophobic; 'Embacel' with $(a)$ aqueous acetore, (b) acetonc; ether. 'Embacel'impregnated with paraffin oil (ref. 8). (a) 30 per cent aqueous acetone, (b) 50-100 per cent aqueous acetone. (4) Reverscd-phase partiacetone, (b) 50-100 per cent aqueous acetone. (4) Reversed-phase partition chromatography using 1so-octanol/chloroform//nethanol/water, cing using iso-amyl acetate/chloroform/methanol/water, $4: 6: 35: 65$. (6) Reversed-phase chromatography using the system deseribed in 4 except that a phosphate buffer of $p H$ 7.2 replaced the water, followed by re-chromatography using system 4. (7) Extraction from chloroform solution with a phosphate buffer $p$ H $7 \cdot 2$ followed by acidifeation and re-extraction into chloroform

* Biossay of the concentrates obtained at each stage on the guinea pig uterus and the rabbit jejunum indicated that the recovery of prostaglandin-like activity in th

carried out in vitro on preparations of guinea pig uterus. human myometrium and rabbit jejunum. Extraction. of the polar lipids was followod by reversed-phase chromatography ${ }^{8}$ to romove the compounds of 'ricinoleic acid type' polarity. This produced a concentrate, $P(3 \cdot 2 \mathrm{~g})$, containing all the components which wore physiologically active on the rabbit jejunum. Fractionation of $I^{\prime}$ using Borgström's first system (Fig. 2) afforded two activo fractions $Q(165 \mathrm{mg})$ and $R(85 \mathrm{mg})$ of contrasting physiological behaviour. Fraction $Q$, a potent stimulant of tho human myometrium (Fig. 3), was highly activo on the rabbit jojunum, but relativoly insutive on the guinea pig uterus. Fraction $R$ either completoly inhibitod or feebly stimulated the contractions of the human myometriun (Fig. 3); it was extremely activo on the guinea pig uterus but only moderately stimulating to the rabbit jejunum.

Separate fractionation of $Q$ and $R$ then followed using Bergström's second system ${ }^{10}$, which is offoctive in discrimi-

(Continued on page 993) 
(Continued from page 960)

nating bstwoon the PGE and PGF types. The main active constituent of $Q$ was concentrated by this means into fractions 10-17 (concentrate $S ; 20 \mathrm{mg}$ ) of a 60-component fractionation (Fig. 4) and chromatographically resembled a PGF. Successive furthor fractionation with change in

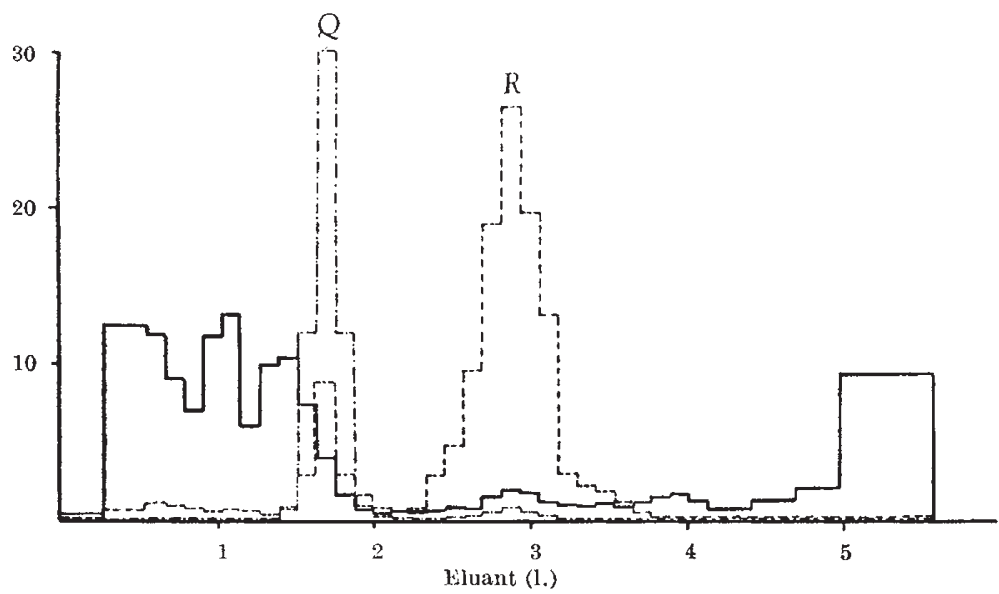

Fig. 2. Reversed-phase partition chromatography of concentrate $P$. Stationary phase: $70 \mathrm{ml}$. iso-octanol/chloroform $(1: 1)$ on $100 \mathrm{~g}$ of hydrophobic 'Embacel'. Moving phase: 47.5 per cent aqueous methanol. - - Weight distribution; abscissa units $1 \mathrm{mg} / \mathrm{ml}$.; on guinea pig uterus; abscissa units $15 \mathrm{ng} \mathrm{HG} \mathrm{E}_{1}$ equiv./ml.

$p \mathrm{H}$ finally produced an acidic coneentrate $U(\sim 0.5 \mathrm{mg})$ showing intense PGF-type activity corresponding to an equivalent content of $2 \mathrm{mg}$ of $\mathrm{PGF}_{1 \alpha}$. A similar process applied to concentrate $R$ lod to concontrate $V(\sim 0.5 \mathrm{mg})$ with pronounced PGE-type activity, corresponding to an equivalent content of $0.2 \mathrm{mg}$ of $\mathrm{PGE}_{1}$.
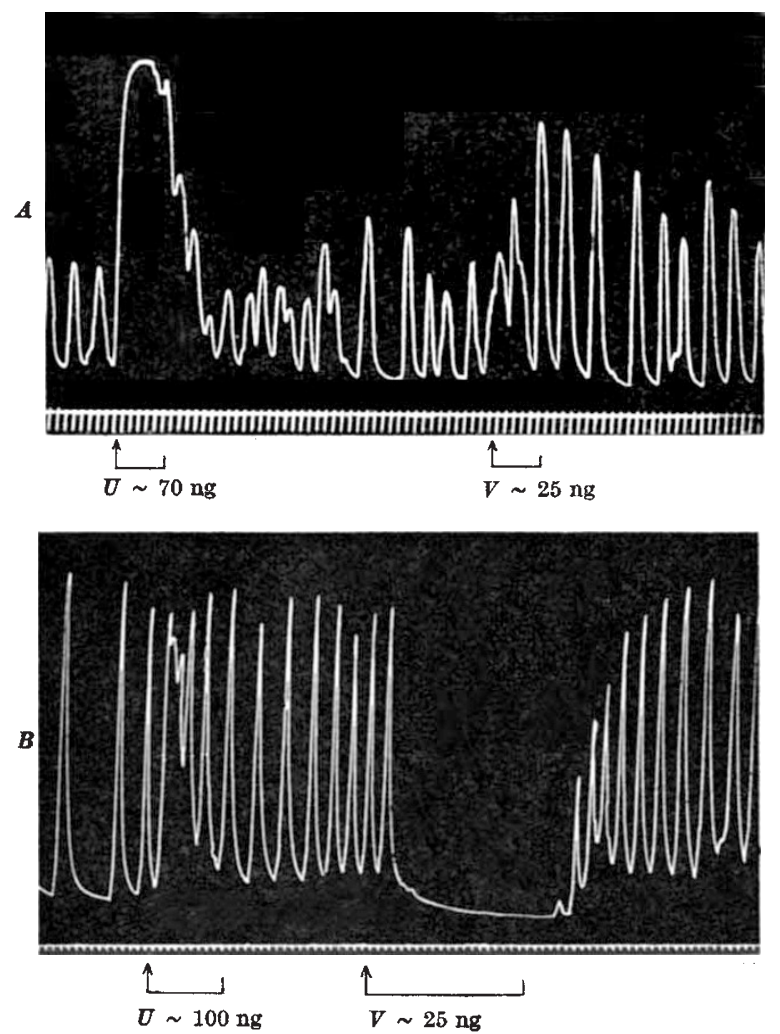

Fig. 3. Effects of menstrual stimulants on human myometrial preparation in vitro (bath-volume $4 \mathrm{ml}$; ; time marker, 1 min). $A$, preparation
showing good positive responses; $B$, preparation showing well-marked
The next step involved the precise identification of the actual active principles in concentrates $U$ and $V$. So far the tentative correlation with the two prostaglandin types had rested on the close parallel between the chromato. graphic behaviour and the typo of biological activity. A routine chemical identification by preparation of derivatives was obviously impossible in view of the minuto amounts of the concentrates $U$ and $V$ available. Accordingly, thin-layer chromatography comparisons were made between the concentrates $U$ and $V$ and authentic samples of $\mathrm{PGE}_{1}, \mathrm{PGF}_{1 \alpha}$ and $\mathrm{PGF}_{1 \beta}$ kindly supplied by Prof. Bergström.

Concentrate $U$ showed a single major spot by thin-layer chromatography which was readily detectable by the characteristic red-brown fluorescence in ultra-violet light which developed after its exposure to acid ceric sulphate, followed by moderate heat; this spot contained the physiologically active substance. Both $\mathrm{PGF}_{1} \alpha$ and $\mathrm{PGF}_{1 \beta}$ gave this colour reaction and the former gave a thin-layer chromatography spot close to that given by this menstrual stimulant of concentrate $U$ (Fig. $5 a$ ).

Treatment of concentrate $U$ with diazomethane gave a relatively inactive product which most significantly showed the characteristic spot (thin-layer chromatography) at a slightly greater $R_{F}$ value than that of authentic PGF ${ }_{1 \alpha}$ methyl ester (Fig. 5b). Location of this spot by an iodine spray ${ }^{11}$ facilitated extraction of the active substance without damage. This product was then exhaustively methyl. ated with diazomethane-boron trifluoride and examined by thin-layer chromatography. The major discrete spot behaved chromatographically in a manner exactly analogous to that shown by $\mathrm{PGF}_{\mathrm{i}} \alpha$ trimethyl ether methyl ester using the hexane-ether system.

At this stage, both the sample and comparison spots of the completely methylated products were extracted, after location by the iodine technique, and the minute amounts of product $(\sim 50 \mu \mathrm{g})$ examined separately by gas liquid chromatography. As may be seen (Fig. 6), the product derived from concentrate $U$ and that derived from $\mathrm{PGF}_{1 a}$ behaved very similarly, although not identically. By comparison of the relative retention volumes with those for standard fatty acids on this non-polar column the observed difference strongly suggested that the menstrual stimulant present in concentrate $U$ was in fact PGF $_{2 a}$ which contains one more double bond than $\mathrm{PGF}_{1 a}$ in the carboxylated side-chain.

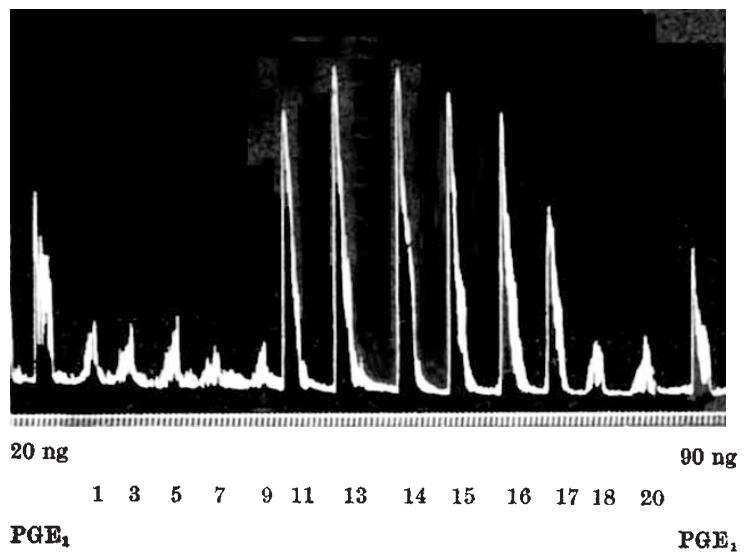

Fig. 4. Rabbit jejunum responses (bath-volume $4 \mathrm{ml}$.; time marker $1 \mathrm{~min}$ ) to $1 / 1,000$ th aliquot of fractions $1-20$ of reversed-phase chromatogram of concentrate $Q$ showing $P G F-$ type in fractions $11-17$ (concentrate 
(a)

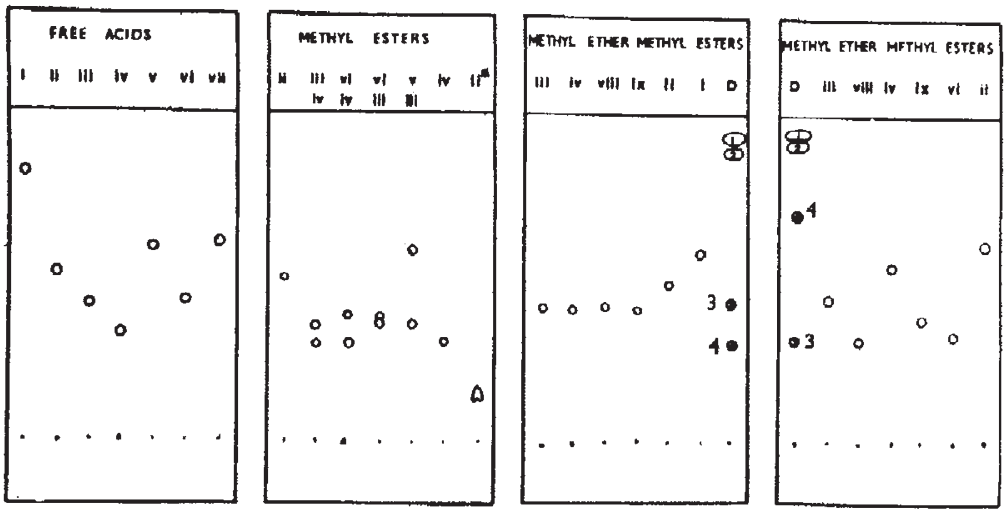

F'ig. 5. Characteristic thin layer chromatograms on $0.2 \mathrm{~mm}$ layers of 'B ieselgel $G$ ' of prostaglandins and allied compounds, a, chloroform/methanol/water, $00: 10: 0 \cdot 5 \mathrm{v} / \mathrm{v}$ Layers made up with $0.2 \mathrm{~N}$ oxalic acid pre-washed with devcloping solvent and developed in saturated atmosphere. $b$, As in (a) except that layer's were made up normally and no pre-washed. Notet tailing of phlolonolic acid (ii ${ }^{*}$ ); $e$, Hexane/ether, $1: 1$; baturated atmosphere development. $l$, Analan chloroform in non-saturated atmosphere. Sub (phloionolic acld); (iii) $\mathrm{PGH}_{2 \alpha}$; (iv) $\mathrm{PGH}_{1 \beta}$; (v) $\mathrm{PG} \mathrm{E}_{1}$; (vi) conecntrate $U$; (vii) concentrate $V$ (viii) least polar borohydride reduction product from concentrato $V$; (ix) most polar borohydride reduction ptoduct from concentrate $V . D$, Dye marker mixture of (1) azobenzene, (2) sudan red, (3) $p$-hydroxyazoben\%ent, (4) $p$-aminoazobenzere
This was sulustantiated by the thin-layer chromatography bohaviour of the trimothyl othor mothyl ester derivatives of $P G F_{1 a}$ and of the menstrual stimulant using silver nitrate complex formation on tho plates ${ }^{22}$. The relative change in $R_{F}$ valuo on formation of tho complex indicated that the menstrual stimulant contained an additional double bond as compared with $\mathrm{PGF}_{1 \alpha}$ and that this doublo bond was probably of the cis configuration.

Final confirmation of this identity with $\mathrm{P}^{2} \mathrm{FF}_{2 \alpha}$ was obtained by mass spectrometric comparison of the trimothyl othor methyl ester dorivativos of $\mathrm{PGF}_{1 \alpha}$ and of the menstrual stimulant.

As only small quantitios of each compound were availablo $(\sim 10 \mu g)$, a special technique was utilized by which tho compounds were introduced directly into the ion source. The spectra wore obtained by an A.E.I. M.S.9 doublo-focusing mass spectromoter and wero run and analysed by Dr. M. Barber and Dr. M. Elliott of A.E.I., Ltd., Manchoster, and Dr. R. I. Reod of this Dopartment, who report as follows.

"The spectrum of $\mathrm{PGF}_{1 a}$ trimethyl ether mothy] estor has already boen roportod ${ }^{13}$ and our spoctrum agreed closely (Fig. 7B). One interesting difference observed by us was the parent molecular ion $\mathrm{M} / \theta=412$ which was not proviously roported.

"The spectrum of the concentrate $U$ derivative was very similar (Fig. 7A). Up to $\mathrm{M} / \Theta=179$ the two spoetra are the same whereas above $\mathrm{M} / \theta=249$ the corresponding ions have a mass two units smaller in the menstrual derivative. The two compounds are therefore of similar structuro, but the concentrate $U$ dorivative contains one more double bond. The cracking pattern is entirely consistent with the assignmont of tho strueture $\mathrm{P} G \mathrm{~F}_{2 \alpha}$ trimothyl ethor methyl oster to this concentrate $U$ derivative."

Concentrate $V$ was similarly examined by thin layer chromatogruphy (Fig. 5a) and showed, after destruetive spraying and heating, a pale-blue spot under ultra-violet light (a characteristic of the PGE family) at a position closoly similar to that simultanously obtainod for an authentic sample of $\mathrm{PCE}_{1}$; the activity of this spot was also shown to be of tho PCE typo.

Sodium borohydride reduction of an nliquot of $V$ (equivalent to $6 \mathrm{\mu g} \mathrm{PGE}_{1}$ ) and examination of the prod. uata by thin-Iavor ehromatography rovoalod that the palo blun spot moving in the PGE region had been converted into two spots olosely comparable in $R_{F^{\prime}}$ value and colour to $\mathrm{P}\left(\mathrm{T}_{7} \mathrm{~F}_{1 \%}\right.$ and $\mathrm{PCF}_{1 \beta}$. This chromatographie change was paralleled by the corresponding change in tho typo of physiological activity which was now only presont in the PGF region of the plate.

The remainder of the concentrate $V$ was similarly reduced and the PGF-type pro. ducts purified using Bergström's socond system. After conversion to the trimethyl othor mothyl estor derivatives the two isomers were resolvod by thin-layer chromatography on 'Kieselgel $G$ ' plates by moans of chloroform (Fig. 5). In this system the $\mathrm{PGF}_{2 \beta}$ derivativo migrates faster than the corresponding $\mathrm{PGF}_{2 a}$ compound ond, although the conditions are difficult to control, rathor remarkablo separations are possible. Final purification of each trimothyl ether methyl ester using the moro consistont, but less selective, hexane ether system was followed by gas liquid chromatograph analysis of the products. One of the isomors was found to be identical with that obtainod from concentrate $U:$ (that is, GPF ${ }_{2 a}$ ) and the other possessed an $R_{F}$ value in accordance with that predictod for $\mathrm{PG} \mathrm{F}_{2 \beta}$. Thus the identity of the menstrual stimulant in concontrate $V$ was confirmed as $\mathrm{PGE}_{2}$.

Tho known occurronco of prostaglindins in human semen ${ }^{9}$ made it highly desirable to excludo the possibility that this might be the source of the prostaglandins in our menstrual fluid samples. Accordingly, a numbor of specimens were examined which were known to be free from this possible adultoration, and which had been collectod in monstrual cups in ordor to avoid any contamination from the usual absorbent materials. They showed physiological, ehromatographic and chemical behaviour identical with those exhibited by the main collection.

The idontification procodures doscribod in this article were carried out on amounts of material ranging from

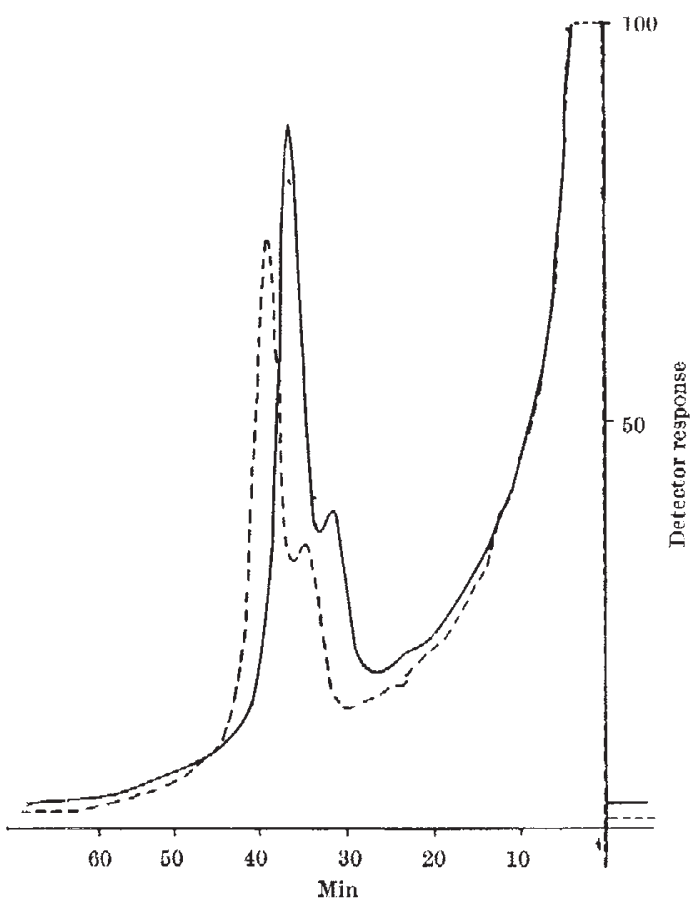

lig. 6. Gas-liguid chromalogrmms of the trimethyl ether methyl ester derived from $(a) \mathrm{PGF}_{a}$ isolated from menstrual thid (--) and

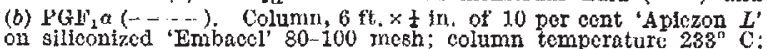

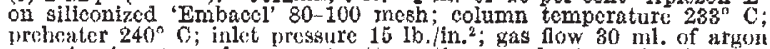
preheater $240^{\circ} \mathrm{C}$; inlet pressure $15 \mathrm{Ib}$./in. ${ }^{2}$; gas flow $30 \mathrm{mil}$. of argon
per min; detector voltage 1,750 ; attenation $\times 1$; loal $0.5 \mu 1$, of $0.2 \mathrm{per}$

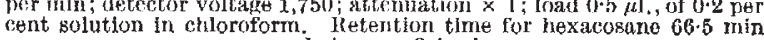
and cleosane 8.4 min 


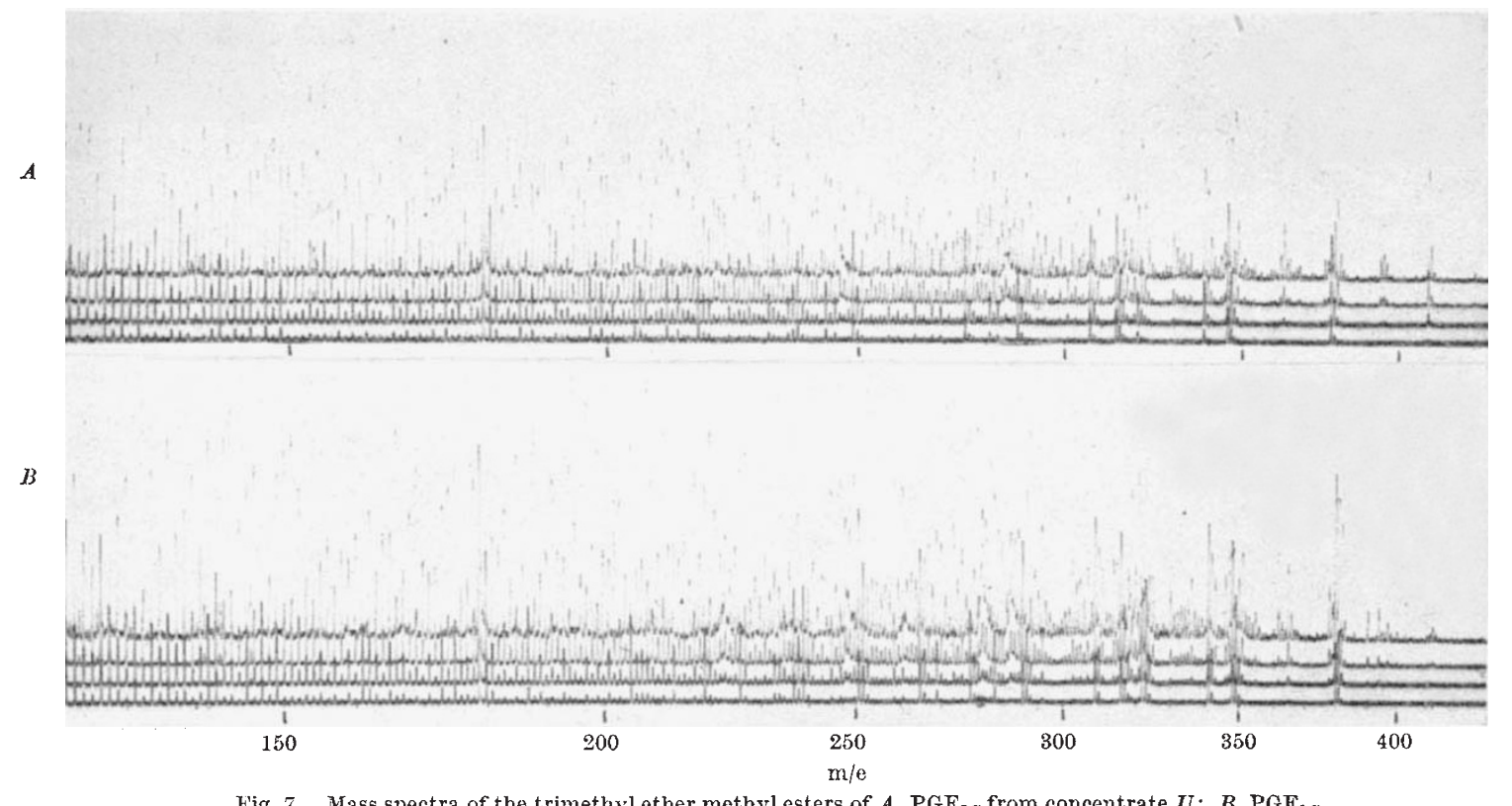

Fig. 7. Mass spectra of the trimethyl ether methyl esters of $A, \mathrm{PGF}_{\mathbf{2} \alpha}$ from concentrate $U ; B, \mathrm{PGF}_{1 \alpha}$

1 to $50 \mu \mathrm{g}$ and demonstrate convincingly the power of modern separation and spectroscopic techniques when allied to physiological potency of such a high order.

The isolation of these two prostaglandins from human menstrual fluid adds this source to the several already described $^{2}$ for this class of compound. From our present results we cannot estimate their concentration in the secretory endometrium; but the yield of $\mathrm{PGF}_{2 a}$ from menstrual fluid is comparable with that obtained by Bergström et al. from pig lung ${ }^{14}$. The quantity of $\mathrm{PGE}_{2}$ is, however, much less than that of the PGE substances in human semen'. The 'menstrual stimulant' prostaglandins in the female may be thought of as homologous to the seminal prostaglandins in the male; however, the wide distribution of smaller amounts of these highly potent substances suggests that they may have some general type of action. For example, Vogt ${ }^{15}$ has suggested that the smooth-muscle contracting long-chain hydroxy-acids may interact with calcium ions, and Clegg, Hopkinson and Pickles ${ }^{16}$ have independently suggested a somewhat similar interaction with magnesium ions.
This work was carried out under the auspices of the Medical Research Council and the National Research laevelopment Corporation. We acknowledge with particuDr gratitude the generous provision of reference samples by Prof. Sune Bergström.

Pickles, V. R., Nature, 180, 1198 (1957).

2 Clitheroe, H. J., J. Physiol., 155, 62 P (1961).

- Baker, J. L., Clitheroe, H. J., and Pickles, V. R., J. Endocrin., 25, i (1962). 'v. Euler, U. S., Arch. Exp. Pathol. Pharmakol. Naunyn-Schmiedeberg's, 175,78 (1934).

s Samuelsson, B., J. Amer. Chem. Soc., 85, 1878 (1963) (and references therein).

- Pickles, V. R., J. Endocrin., 19, 150 (1959).

${ }^{7}$ Clitheroe, H. J., and Pickles, V. R., J. Physiol., 156, 225 (1961).

8 Howard, G. A., and Martin, J. P., Biochem. J., 46, 532 (1950).

- Bergström, S., and Samuelsson, B., J. Biol. Chem., 237, PC, 3005 (1962).

${ }^{10}$ Bergström, S., and Sjövall, J., Acta Chem. Scand., 14, 1701 (1960).

"Matthews, J. S., Pereda, V., and Amada Aguilera, P., J. Chromatog., 9, 331 (1962).

12 Morris, L. J., Chem. and Indust., 27, 1238 (1962).

${ }^{13}$ Bergström, S., Krabisch, L., Samuelsson, B., and Sjövall, J., Acta Chem. Scand., 16, 972 (1962).

${ }^{14}$ Bergström, S., Dressler, F., Krabisch, I., Ryhage, R., and Sjövall, J., Arkiv. Kemi, 20,63 (1963).

${ }^{15}$ Vogt, W., Biochem. Pharmacol., 12, 415 (1963).

${ }^{10}$ Clegg, P. C., Hopkinson, P., and Pickles, V. R., J. Physiol., 167, 1 (1963).

\section{ANOMALY OF ALDOLASE IN PRIMARY LIVER CANCER \\ BY FANNY SCHAPIRA, JEAN-CLAUDE DREYFUS and GEORGES SCHAPIRA Laboratoire de Recherches de Biochimie Médicale, Hôpital des Enfants-Malades, Paris}

$\mathrm{R}$ ESEARCH in enzymology has been more extensive in experimontal cancer than in human cancer, quantitative investigations not always being valid in postmortem cases and biopsies not always being possible.

The discovery of multiple molecular forms of the enzymes named by Markert and Moller "isozymes"1 enabled us to re-orient this research on a new basis. In the animal, Angeletti and Moore ${ }^{2,3}$ have shown three peaks for glucose-6-phosphate dehydrogenase of mouse rhabdomyosarcoma, by chromatography on substituted celluloses, instead of one poak in the normal muscle; they have obtained analogous results on the acid phosphatase of the rat hepatoma, in which the chromatographic pattern is different from that of normal liver.

In man, Starkweather and Schoch ${ }^{4}$, removing cancers of diverse origins a few hours after death, found that the distribution of the five isozymes of lactic-dehydrogenase, very varied in normal tissue, tended to become uniform and to predominate in one peak in cancer tissue.

The mode of action on the two substrates, fructose-1,6diphosphate and fructose-1-phosphate, of aldolase from different tissues, and more particularly of hepatic aldolase, has given us a new approach for the enzymological examination of hepatomas.

One of us, with Payet ${ }^{5}$, had, in 1960, pointed out that hyperaldolasæmia in the course of a primary liver cancer was not of the hepatic type, in the sense that the ratio of the two aldolase activities, fructose-1,6-diphosphoaldolase and fructose-1-phosphoaldolase $\left(\frac{\text { F-1,6-P }}{\text { F-1-P }}\right)$ was in the range of 3 , instead of 1 or nearly 1 as in the hepatic type; this ratio of 1 being that found in the normal liver. We had at that time suggested the following interpretation: hyperaldolasæmia comes from the 